CONF-911202--81

DE92 015603

\title{
HIERARCHICAL CELLULAR MATERIALS
}

\author{
L.J. GIBSON \\ Department of Civil Engineering \\ Massachusetts Institute of Technology \\ Cambridge, MA 02139
}

MATERIALS RESEARCH SOCIETY

FALI MEETING 1991

SYMPOSIUM Z

HIERARCHICALLY STRUCTURED MATERIALS

NOVEMBER 1991

FG02-902ER45422

\section{DISCLAIMER}

This report was prepared as an account of work sponsored by an agency of the United States Government. Neither the United States Government nor any agency thereof, nor any of their employees, makes any warranty, express or implied, or assumes any legal liability or responsibility for the accuracy, completeness, or usefulness of any information, apparatus, product, or process disclosed, or represents that its use would not infringe privately owned rights. Refer. ence herein to any specific commercial product, process, or service by trade name, trademark, manufacturer, or otherwise does not necessarily constitute or imply its endorsement, recommendation, or favoring by the United States Government or any agency thereof. The views and opinions of authors expressed herein do not necessarily state or reflect those of the United States Government of any agency thereof.

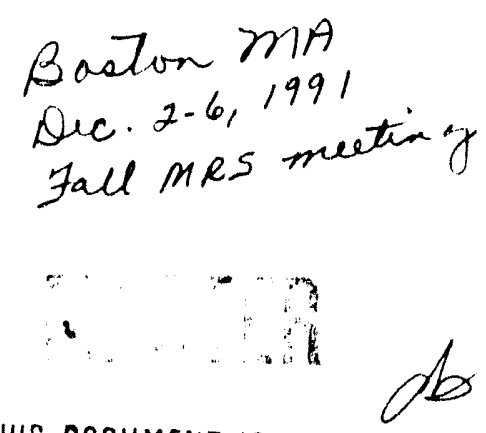

DiSTRIZUTION OF THIS DOCUMENT IS UMLIMITED 


\section{HIERARCHICAL CELLULAR MATERIALS}

\section{Introduction}

Cellular materials are made up of an interconnected network of struts or plates. They are widespread in nature: for instance, wood, cork and caricellous bone all have a cellular structure. In the last 50 years, engineers have made their own cellular materials in the form of honeycombs, with two-dimensional, prismatic cells, and fcams, with threedimensional, polyhedral cells. Today, both honeycombs and foams can be made from every class of materiai: polymers, metals, ceramics and glasses. Their cellular structure gives rise to unique properties which are exploited in engineering design. Their low density makes them ideal for buoyancy devices and for the cores of structural sandwich panels; their low strength, combined with their capacity to undergo large strains, makes them excellent energy absorbers for packaging and protective padding, and their low thermal conductivity makes them the best insulating material available.

The properties of cellular solids depend on three variables: the relative density of the material, equivalent to the volume fraction of solid; the properties of the cell wall material; and the geometry of the cells (cell size, prismatic or polyhedral, open or closed, equiaxed or anisotropic). The most notable difference between natural and engineering cellular solids is that those occuring in rature tend to have composite cell walls while engineered cellular solids have cell walls made of a single material: natural cellular solids have a hierarchical structure. For instance, the cell wall of wood is a composite of semicrystalline cellulose microfibrils in a matrix of lignin and hemicellulose and that of cancellous bone is a composite of collagen fibrils in a matrix of hydroxyapatite. 
In this paper a method for estimating the contributions of both the composite and the cellular microstructures to the overall material properties and the mechanical efficiency of natural cellular solids will be described. The method will be demonstrated by focussing on the Young's modulus; similar techniques can be used for other material properties. The results suggest efficient microstructures for engineered cellular materials.

\section{Models for Composite and Cellular Materials}

The Young's modulus of a composite material can be estimated using the familiar upper and lower bounds, Eupper and Elower, respectively:

$$
E_{\text {upper }}=E_{1} V_{2}+E_{2} V_{2}
$$

and

$$
E_{\text {lower }}=\frac{E_{1} E_{2}}{E_{1} V_{2}+E_{2} V_{1}}
$$

where $E_{1}$ and $E_{2}$ are the Young's moduli, and $V_{1}$ and $V_{2}$ are the volume fractions of phases 1 and 2 . The upper and lower bounds give good estimates of the moduli for aligned, unidirectional composites for loading parallel and perpendicular to the fibres, respectively. The moduli of random fibre composites, or of particulate composites, lie between these two bounds. The density of the composite, $\rho_{c}$, is given by:

$$
\rho_{:}=\rho_{2} V_{1}+\rho_{2} V_{2}
$$

where $\rho_{1}$ and $\rho_{2}$ are the densities of phases 1 and 2 . 
The Young's moduli of cellular materials are estimated by analyzing the elastic deformation of the cells under uniaxial stress. I'he in-plane young's moduli of a honeycomb is controlled by bending of the cell walls, leading to (Fig. 1) (Gibson and Ashby, 1988):

$$
E_{1,2} \propto E_{s}\left(\rho / \rho_{s}\right)^{3}
$$

The out-of-plane Young's moduli of a honeycomb is controlled by axial deformation of the cell walls, leading to (Fig. 1):

$$
E_{3} \propto E_{s}\left(\rho / \rho_{s}\right)
$$

where $E_{1}, E_{2}$ and $E_{3}$ are the Young's moduli of the honeycomb for loading in the $x_{1}, x_{2}$ and $x_{3}$ directions (Fig. 1), $E_{s}$ is the Young's modulus of the solid cell wall material, and $\rho$ and $\rho_{\mathrm{s}}$ are the densities of the honeycomb and the solid, respectively. The Young's modulus of an open cell foam is governed by cell wall bending, leading to (Gibson and Ashby, 19881 :

$$
E \propto E_{s}\left(\rho / \rho_{2}\right)^{2}
$$

\section{Performance indices and material selection charts}

Performance indices can be used to identify materials which minimize the weight (or volume, or cost) of a component under a given loading. For instance, for a tie rod of a given axial stiffness, the mass of the component is minimized by selecting the material with the maximum value of the performance index $E / \rho$. For a beam of a given flexural stiffness, the mass of the component is minimized by selecting the material with the maximum value of $E / \rho^{2}$. (The 
stiffness, $S_{b}$, of the beam of span, 1 , and cross-sectional moment of inertia, $I$, is given by:

$$
S_{b} \propto \frac{E I}{1^{3}}
$$

The mass of the beam is given by:

$$
m \propto \rho A l
$$

or,

$$
m \propto \frac{\rho}{E^{1 / 2}}\left(S_{b} I^{5}\right)^{1 / 2}
$$

The mass of the beam is minimized by selecting the material with the largest value of $E / P^{2}$.) And for a plate of a given flexural stiffness, the mass is minimized by selecting the material with the maximum value of $E / P^{3}$. Performance indices for other mechanical requirements and other loading configurations are given by Charles and Crane, 1989 and Ashby, 1989 .

A plot of the moduli against the densities of materials, on double logarithmic scales, can be used to identify the materials which minimize the mass of a component for a given stiffness: such a plot is an example of a material selection chart (Fig. 2). A straight line of slope 1 on the plot identifies materials with equal values of $E / P$; all are equally efficient for a tie rod of a given axial stiffness. A straight line of slope 2 on the plot identifies materials witi equal values of $E / \rho^{2}$, all are equally efficient for a beam of a given flexural stiffness. Lines toward the upper left corner of the diagram have higher values of the performance indices than those towards the lower right. The plot can be used to identify the material which minimizes the 
weight of a component of a given stiffuess for a given loading configuration. For example, a single ply of unidirectional carbon fibre reinforced plastic (CFRP) composite has a value of $\mathrm{E} / \mathrm{p}^{2}$ of almost $100 \mathrm{GPa} /\left(\mathrm{Mg} / \mathrm{m}^{3}\right)^{2}$ for loading in the fibre direction while laminated glass fibre reinforced plastic (GFRP) composite has a value of $E / p^{2}$ of about $10 \mathrm{GPa} /\left(\mathrm{Mg} / \mathrm{m}^{3}\right)^{2}$. Balsa, the lowest density wood, has a value of $E / \mathrm{p}^{2}$ greater than $100 \mathrm{GPa} /\left(\mathrm{Mg} / \mathrm{m}^{3}\right)^{2}$, higher than that of unidirectional CFRP. A balsa beam has a greater flexural stiffness than a CFRP one of the same mass and crosssectional shape. How does this high mechanical efficiency arise? Are other natural materials highly efficient? If so, how does their efficiency arise?

Another materials selection chart, plotting $E$ against $\rho$ for natural materials, is shown in Fig. 3. Balsa has the highest value of $E / \rho$. But other natural cellular materials, such as palm and bamboo, also rank highly.

A third materials selection chart, showing data for wood along with those for its components, is shown in Fig. 4. The figure indicates how both the composite and the cellular microstructures contribute to the efficiency of wood. First consider the composite nature of the cell wall with semicrystalline ceilulcse fibrils embedded in an amorphous matrix of lignin and hemi-zellulose. The upper and lower bounds (eqn 1 and 2) for the composite modulus lie between the values for celluluse ( $E=75 \mathrm{GPa}$ ) and the matrix $(E=2 \mathrm{GPa})$. Measured values are between 10 and $35 \mathrm{GPa}$ (Cave 1968). The densities of cellulose, lignin and hemi-cellulose are all around $1.5 \mathrm{mg} / \mathrm{m}^{3}$, leading to a composite wood cell wall density of the same value. Next consider the cellulax structure of wood. The bulk of the cells in wood can be modelled roughly as prismatic hexagonal cells like those of a honeycomb. Their modulus for loading along the grain varies linearly with density (eqn 5). Data for a variety of woods, 
plotted on the materials selection chart of Fig. 4 lie along a line of slope 1, consistent with this model. A reduction in density by a factor of 10 then reduces the modulus by an equal factor of 10 and the square of the density by a factor of 100 , resulting in a 10 -fold increase in the value of $E / \mathrm{p}^{2}$. This accounts for the high value of $E / \mathrm{p}^{2}$ of low density balsa wood.

The idea is shown schematically for an engineering materials in Fig. 5. Two components, $A$ and $B$, form $a$ composite cell wall with a modulus intermediate to the upper and lower bounds. The composite cell wall is then fabricated into a prismatic honeycomb-like cellular material with a modulus for loading along the prism axis directly proportional to the density. The lower the density of the composite honeycomb, the higher its value of $E / \rho^{2}$, and the more efficient the material is for a beam of given flexural stiffness. Fabricating the composite into a foam has no effect on its value of $\mathrm{E} / \mathrm{p}^{2}$ since the modulus of the foam varies with the square of its density (eqn 6 ). But the value of $E / \rho^{3}$ does increase for a low density foam, suggesting that it is an efficient material for a plate of a given flexural stiffness. Note that although the value of $E / \rho^{3}$ for $a$ honeycomb is higher than that for the foam, the composite honeycomb does not have equal moduli in the plane of the plate, reducing its efficiency as a plate material.

Data for the modulus, density and performance indices $E / \rho, E / \rho^{2}$, and $E / \rho^{3}$ for engineering materials are shown in Table l. For the component material, $E / P>E / \rho^{2}>E / \rho^{3}$. For the composite material, each performance index lies between those of its components. But for the cellular materials, $E / P$ $<E / P^{2}<E / P^{3}$ : reducing the density increases the efficiency of the material for beam flexural stiffness (honeycomb) and plate flexural stiffness (foam). Table 2 lists the data for wood and its components, showing the same trend. 
4. Desian of Compesite Cellular Materials

The observations of the last section suggest that efficient materials for a beam of a given flexural stiffness could be made by assembling sections made up of composite tubes, with the tube axis running along the length of the beam. Values of $E / \rho$ and $E / \rho^{2}$ for new engineering materials, made up of CFRP tubes with 0.5 and 0.2 volume fraction of solids, are listed in table $3 . E / P$ is constant at 90 $\mathrm{GPa} /\left(\mathrm{Mg} / \mathrm{m}^{3}\right)^{2}$, equal to the value for fully dense CFRP. But $\mathrm{E} / \mathrm{\rho}^{2}$ increases from 50 to $260 \mathrm{GPa} /\left(\mathrm{Mg} / \mathrm{m}^{3}\right)$ for the lower density material.

Clearly the density of the composite cellular material cannot be reduced indefinitely. The lower limit is controlled by the strength of the material: local buckling of very thin walled tubes can occur at unacceptably low loads. In nature, local buckling is suppressed in three ways: by the presence of lateral membranes, as septa, across the cell void at a regular spacing (eg. bamboo); by filling the void with low density, foam-like cells of smaller scale which act as an elastic foundation (eg. hawthorn); and by internally pressurizjng the cells (eg. chive, dandelion stem). Advanced composite cellular materials may mimic these features of natural cellular materials, too.

\section{Acknowledgements}

We are grateful to Ros olive of Cambridge University Engineering Department for assistance in compiling data for Fig. 3 and to Ms. Sheila owen for preparation of Figs. 2-4. The U. S. Department of Energy and the NATO Program for International Collaborative Research provided funding for this work. 


\section{References}

Ashby, M. F. (1989) Acta Metall. 37, 1273.

Cave, I.D. (1968) Wood Science and Tech. 2 , 268.

Charles, J.A. and Crane, F.A.A. (1989) Selection and Use of Engineering Materials Butterworths.

Gibson, J. J. and Ashby, M. F. (1988) Cellular Solids: Structure and Properties. Pergamon Press. 
TABLE 1 PERFORMANCE INDICES FOR STIFENESS:

ENGINEERING MATERIALS

\begin{tabular}{lccccc} 
Material & $\begin{array}{l}E \\
\text { (GPa) }\end{array}$ & $\begin{array}{c}\rho \\
\left(\mathrm{Mg} / \mathrm{m}^{3}\right)\end{array}$ & $\mathrm{E} / \rho$ & $\mathrm{E} / \mathrm{\rho}^{2}$ & $\mathrm{E} / \mathrm{\rho}^{3}$ \\
\hline & & & & \\
Component materials & & & & \\
Carbon fibre & 390 & 1.95 & 200 & 100 & 53 \\
Glass fibre & 76 & 2.56 & 30 & 12 & 4.5 \\
Epoxy & 5 & 1.30 & 3.8 & 3 & 2.3 \\
Aluminum & 70 & 2.70 & 26 & 10 & 3.5 \\
Polyurethane & 1.6 & 1.20 & 1 & 1 & 0.9
\end{tabular}

Composite materials

$\begin{array}{lrrrrr}\text { CFRP uniply } & 150 & 1.70 & 88 & 52 & 30 \\ \text { GFRP laminates } & 25 & 1.50 & 16 & 11 & 7\end{array}$

Cellular materials

Aluminum

honeycomb

$1.4 \quad 0.054$

26

480

8900

Polyurethane

foam

$0.016 \quad 0.12$

0.13

1.1

9.3 
TABLE 2 PERFORMANCE INDICES FOR STIEFNESS; NATURAL MATERIALS

\begin{tabular}{cccccc} 
Material & $E$ & $\rho$ & $E / \rho$ & $E / \rho^{2}$ & $E / \rho^{3}$ \\
& $(\mathrm{GPa})$ & $\left(\mathrm{Mg} / \mathrm{m}^{3}\right)$ & & & \\
\hline
\end{tabular}

Component materials

$\begin{array}{llllll}\text { Cellulose } & 100 & 1.5 & 66 & 44 & 30\end{array}$

$\begin{array}{llllll}\text { Matrix (lignin) } & 2 & 1.5 & 1.3 & 0.9 & 0.6\end{array}$

Composite material

$\begin{array}{llllll}\text { Wood cell wall } & 35 & 1.5 & 23 & 15 & 10\end{array}$

Cellular composite material

$\begin{array}{llllll}\text { Oak } & 15 & 0.6 & 25 & 42 & 69\end{array}$

$\begin{array}{llllll}\text { Balsa } & 3 & 0.15 & 20 & 133 & 888\end{array}$ 
TABLE 3 PEREORMANCE INDICES EOR STIEFNESS: CELLULAR COMPOSITE ENGINEERING MATERIALS

\begin{tabular}{lccccc} 
Material & $\begin{array}{c}E \\
\text { (GPa) }\end{array}$ & $\begin{array}{c}\rho \\
\left(\mathrm{Mg} / \mathrm{m}^{3}\right)\end{array}$ & $E / \rho$ & $E / \rho^{2}$ & $E / \rho^{3}$ \\
\hline Solid CFRP & 150 & 1.70 & 90 & 52 & 30 \\
CFRP tubes & & & & & \\
$\mathrm{V}_{\mathrm{S}}=0.5$ & 75 & 0.85 & 90 & 100 & 120 \\
$\mathrm{~V}_{\mathrm{S}}=0.2$ & 30 & 0.34 & 90 & 260 & 760
\end{tabular}




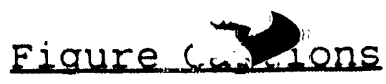

Fig. 1 (a) A two-dimensional honeycomb with prismatic hexagonal cells.

Fig. 1 (b) A three-dimensional foam with polyhedral cells.

Fig. 2 A materials selection chart, plotting Young's modulus $E$, against density, $\rho$, for engineering materials.

Fig. 3 A materials selection chart for natural materials.

Fig. 4 A materials selection chart for woods and their components.

Fig. 5 Schematic materials selection chart for composite cellular materials. 


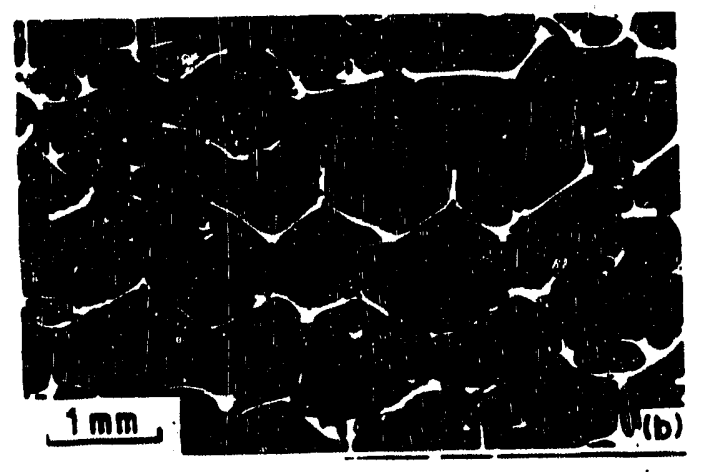

$E \propto E_{S}\left(\rho / \rho_{S}\right)^{2}$

Figure 1(a). A two-dimensional honeycomb with prismatic hexagonal cells.

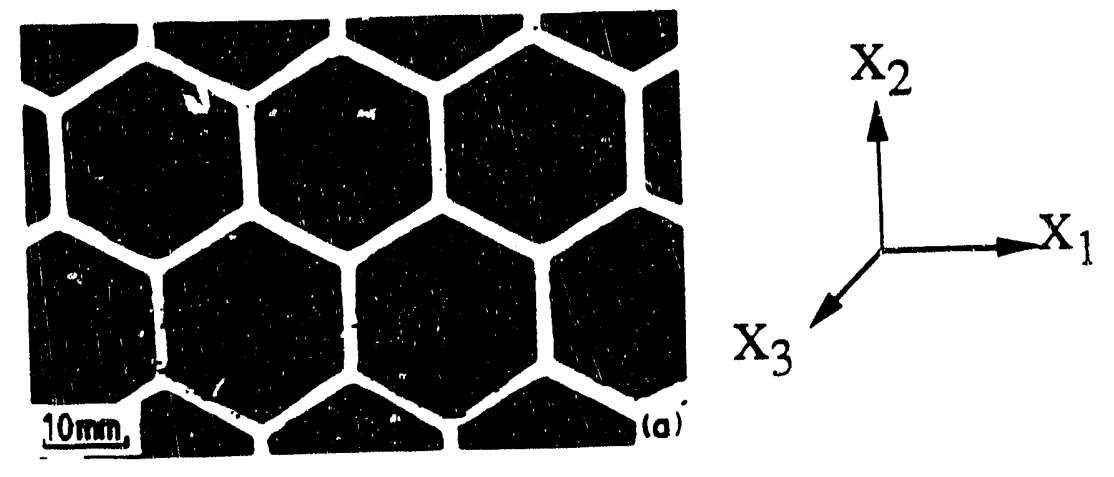

$E_{1} \alpha E_{S}\left(\rho / \rho_{s}\right)^{3}$

$E_{3} \propto E_{S}\left(\rho / \rho_{S}\right)$

Figure 1(b). A three-dimensional foam with polyhedral cells. 


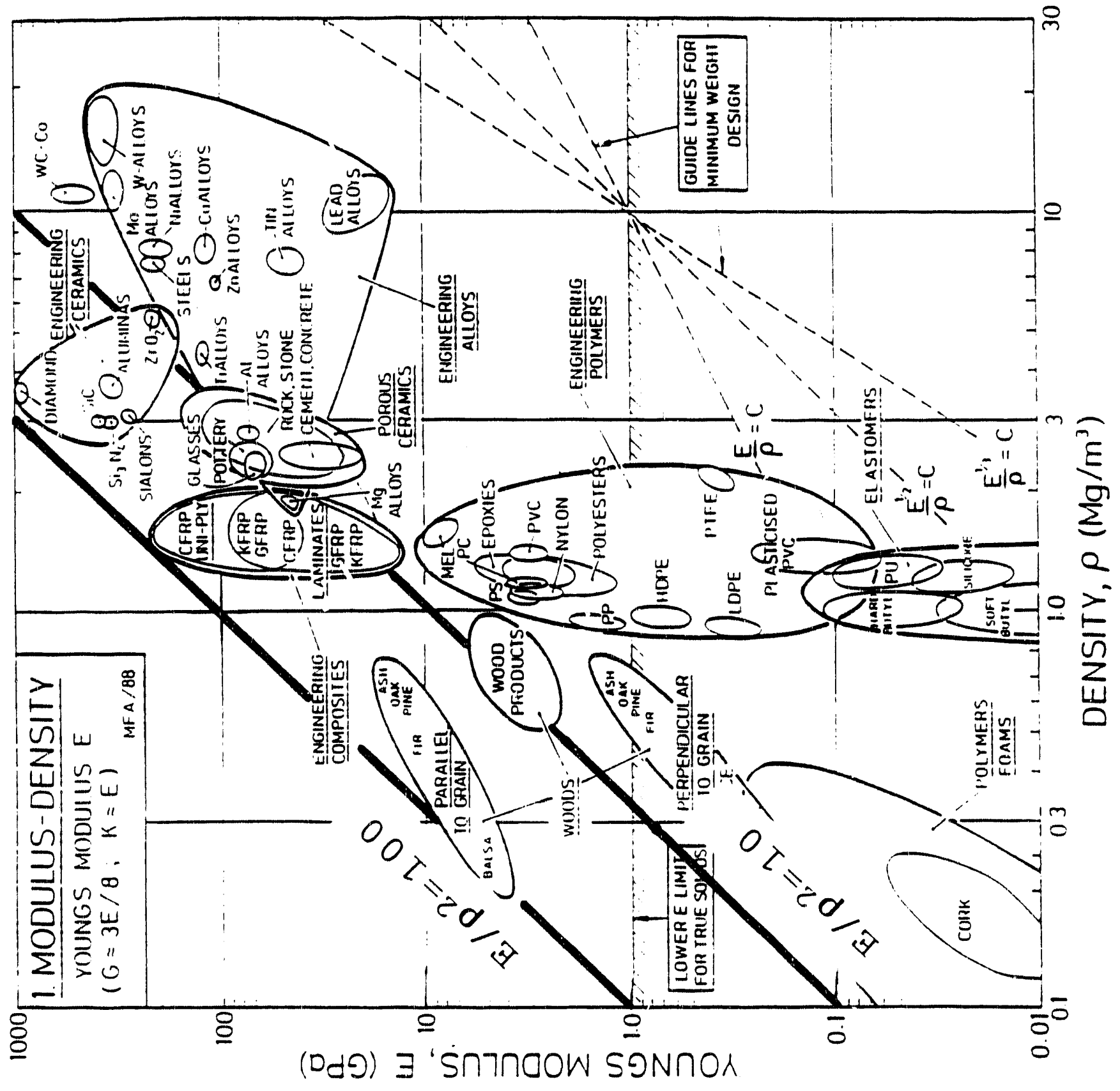

Fig. 2 A materials selection chart, plotting Young's modulus $E$, against density, $p$, for engineering materials. 


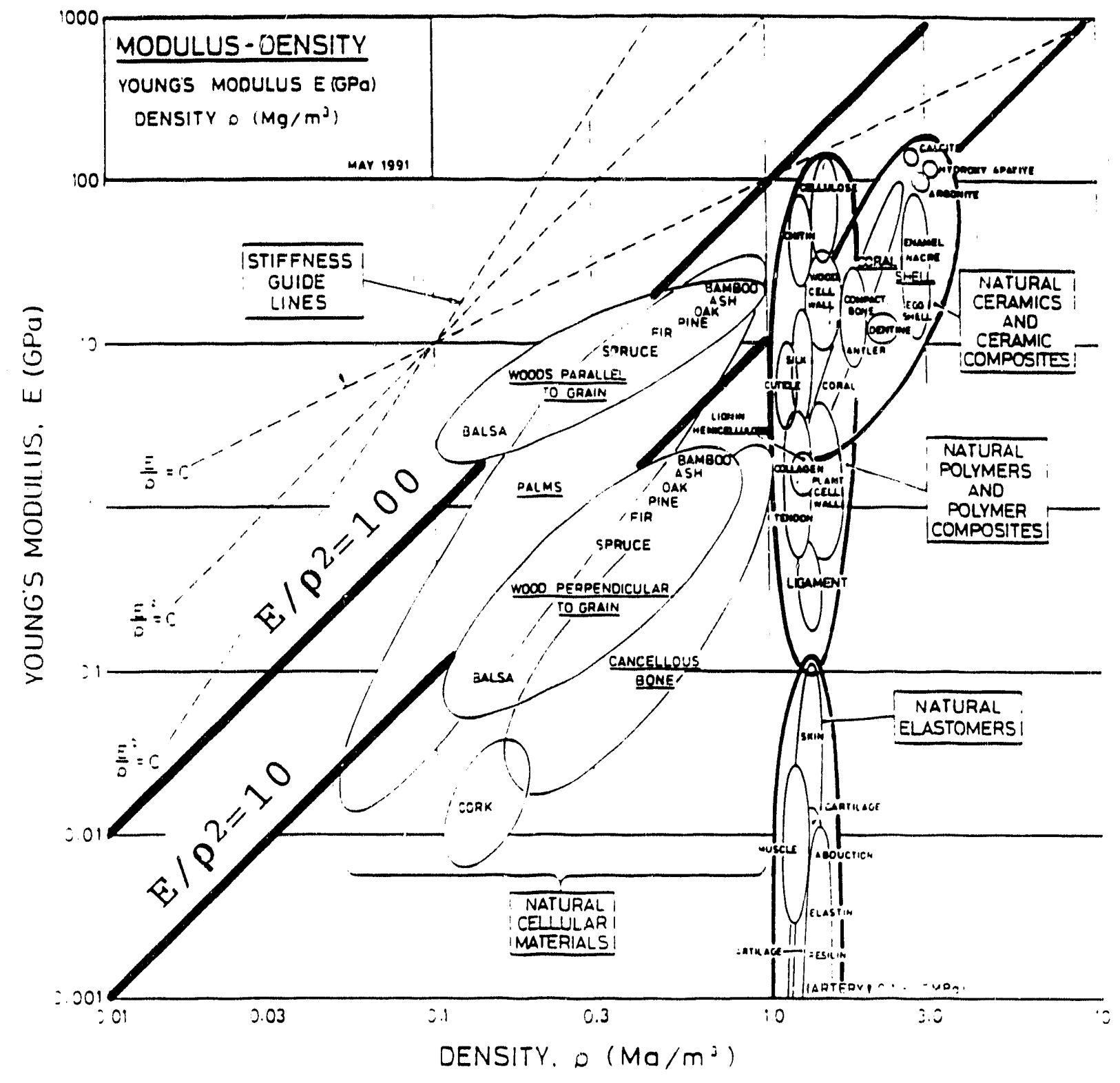

Fig. 3 A materials selection chart for natural materials. 


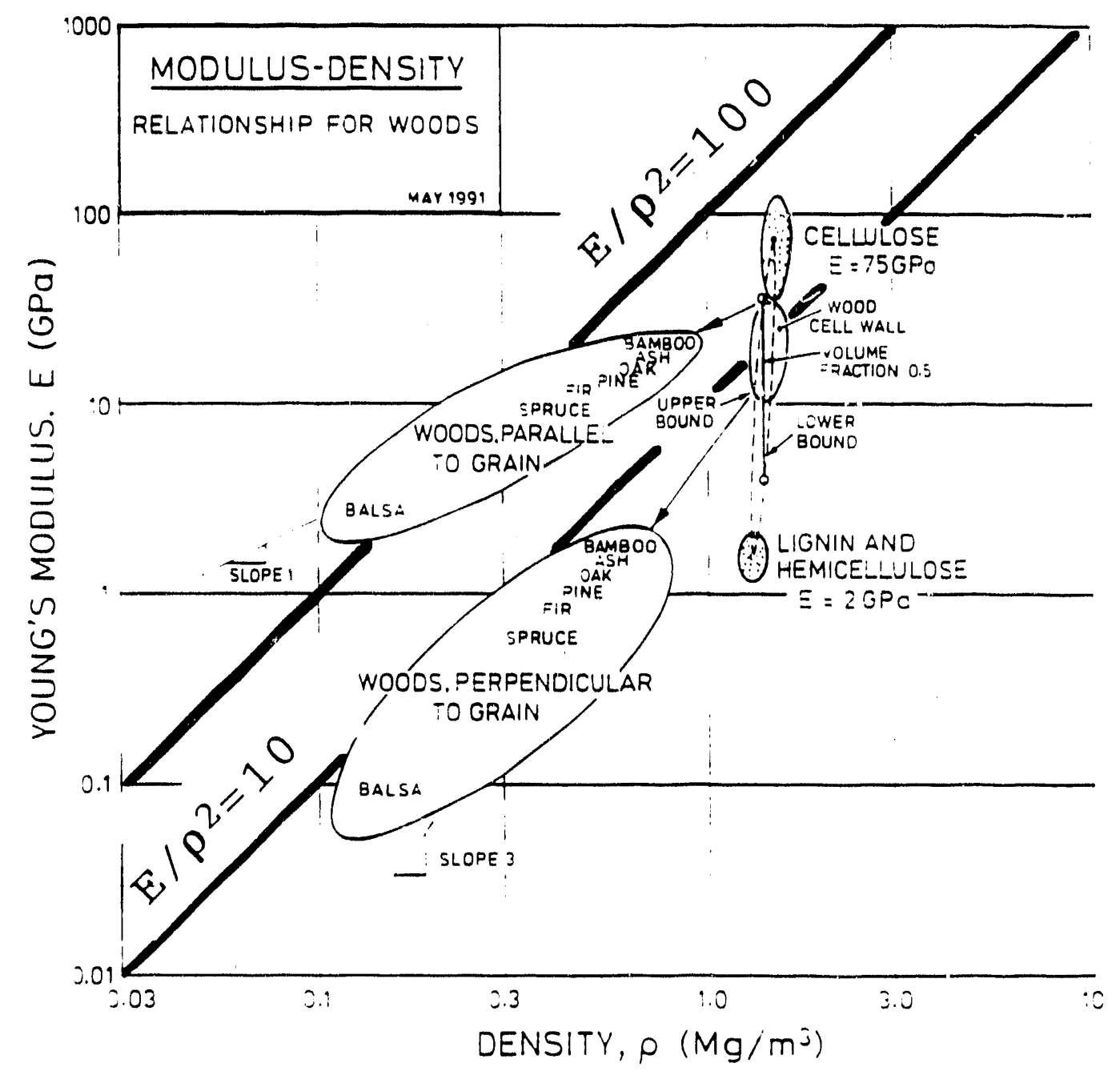

Fig. 4 A materials selection chart for woods and their components. 


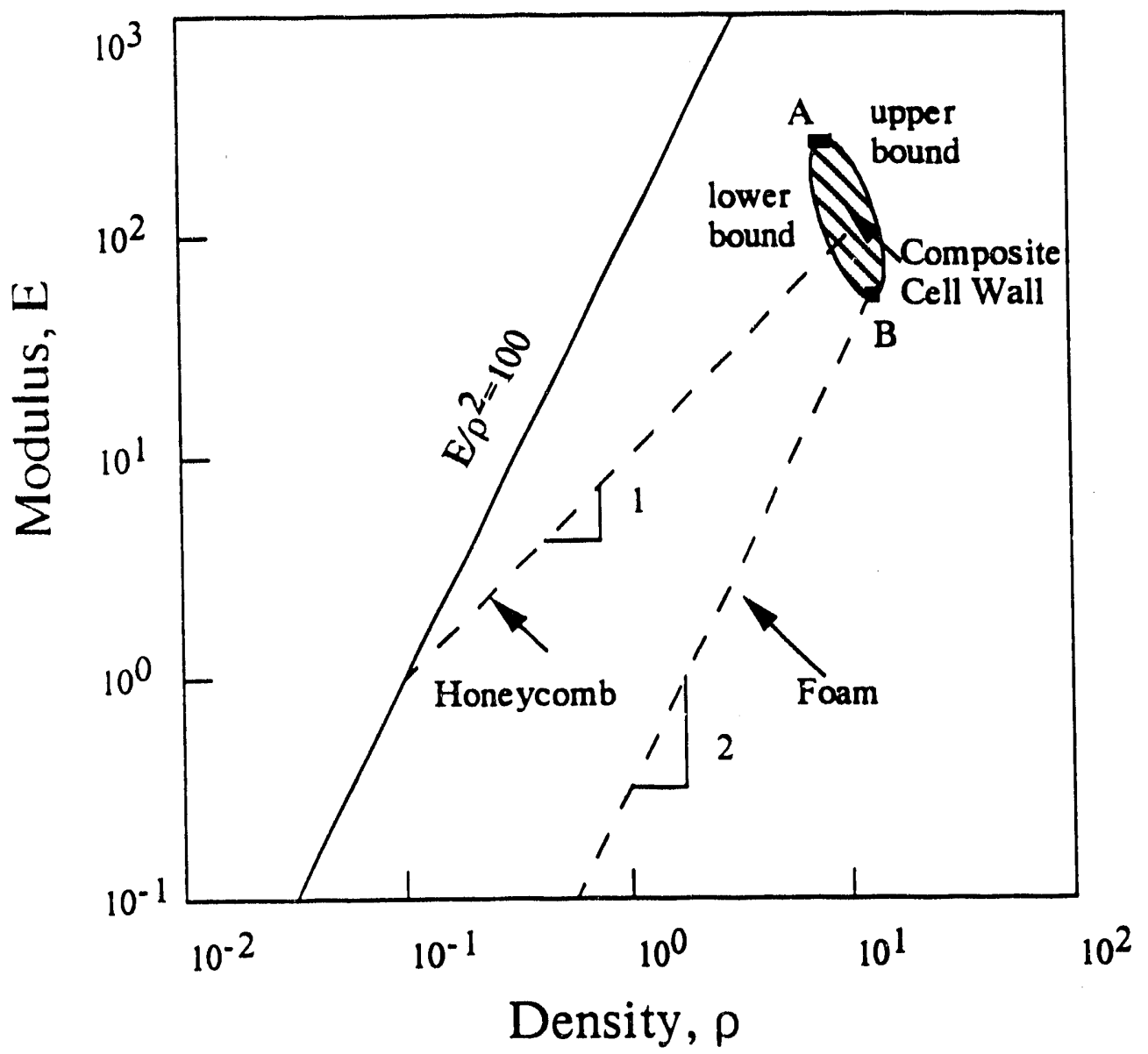

Fig. 5 Schematic materials selection chart for composite cellular materials. 

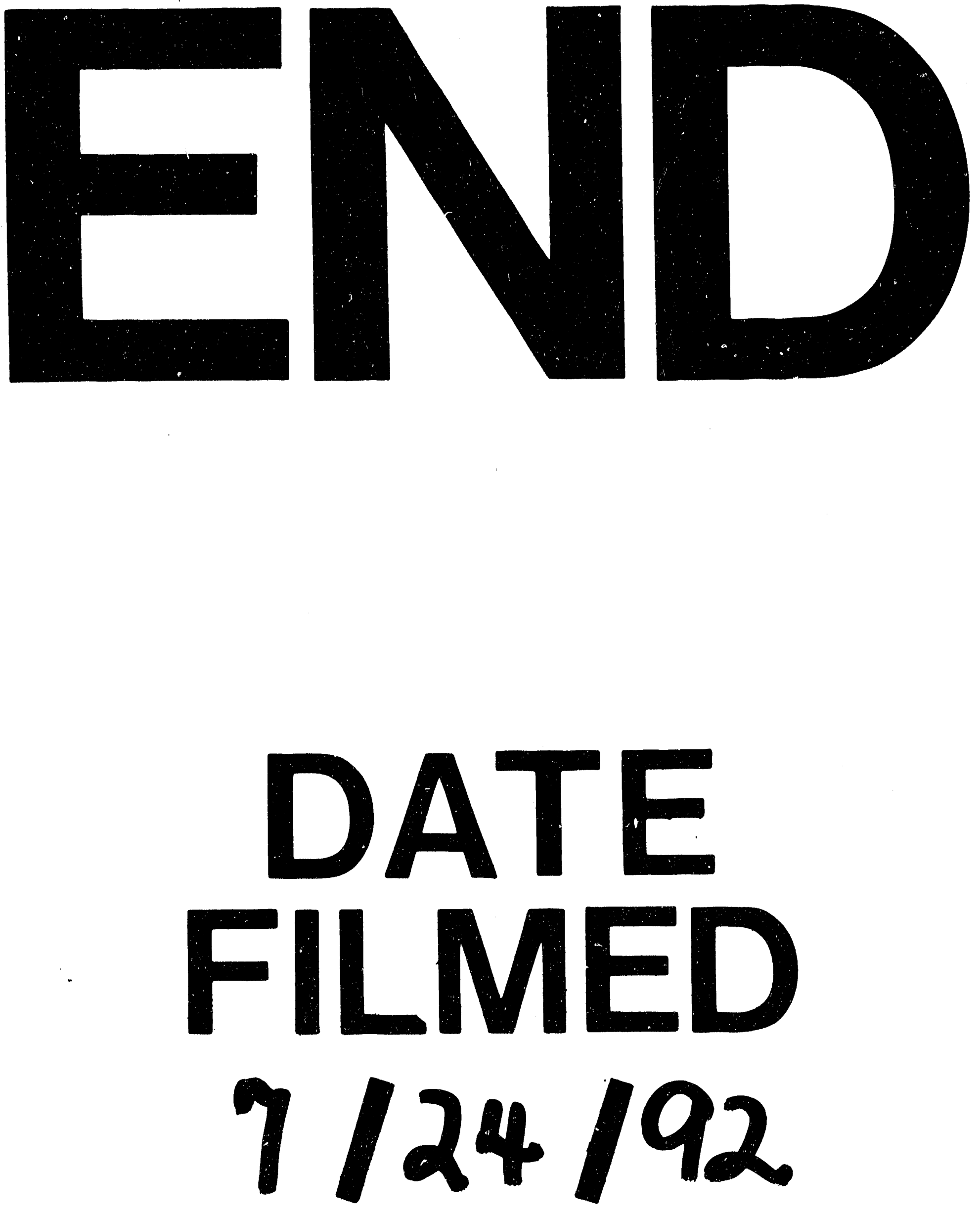

I 
